\title{
Advance Care Planning in Oncology - Ethical and Medical Competences Are Needed
}

\author{
Jan Schildmann ${ }^{a, b}$ Eva C. Winkler ${ }^{b, c}$ \\ anstitute for Medical Ethics and History of Medicine, NRW-Junior Research Group 'Medical Ethics at the End of Life: Norm and Empiri- \\ cism', Ruhr University Bochum; 'Working Group 'Medicine and Ethics', German Society of Hematology and Oncology; 'National Center for \\ Tumor Diseases, Programme for Ethics and Patient-Oriented Care, University of Heidelberg, Germany
}

\section{Keywords}

Advance care planning $\cdot$ Medical ethics $\cdot$ Communication skills

Editor - we would like to thank Hubert et al. [1] for their publication on empirical evidence regarding the current state of advance directives in Germany, as well as Jürgen in der Schmitten [2] for his thoughtful editorial focus on advance care planning. While we agree with both authors that communication about end-of-life preferences is an important prerequisite for good clinical care at the end of life, we believe that it is also important to clarify the roles of oncologists and other healthcare professionals in end-of-life decision making in the context of cancer care.

First of all, and relevant for the impact of advance directives as an instrument in oncology, it should be pointed out that the majority of cancer patients have the legal capacity to make competent treatment decisions up to the last days of life. Hence, in most cases, end-of-life decisions are based on the present will of the patient, and no reference to an often vague document is required. Secondly, advance directives should not be simply discarded in the course of advocating the more process-oriented model of advance care planning. After all, advance directives have an important legal function in documenting patient preferences which should be considered when making a decision in a situation where the patient can no longer communicate his/her wishes. Moreover, and relevant from a practical point of view, addressing and completing an advance directive can be used as starting point for discussing and learning about a patient's preferences. Regardless of the trigger used to start discussions about end-of-life decision making, it is important that oncologists with their medical knowledge and experience take on the task of preparing the patient by addressing the prognosis and treatment options early enough and in crucial moments of the disease trajectory [3]. Thirdly, and in addition to the medical expertise relevant for identifying an appropriate moment for advance care planning, end-of-life discussions require professional ethical and communication competences. Identifying preferences and deliberating about treatment decisions which are medically informed and at the same time reflect the patient's values can be difficult to put into practice and may be even more challenging if oncologists have not received training to develop the necessary skills, as is largely the case in Germany.

In conclusion, we support the procedural concept of advance care planning involving other healthcare professionals as an option to strengthen consideration for patient preferences. However, due to the medical expertise relevant for such decision making, but also in light of the trust cancer patients place in their physicians [4], we argue that oncologists cannot restrict their professional tasks to the medical-technical side of cancer treatment. Rather, oncologists need to inform cancer patients and facilitate professional end-of-life decision making based on both their practical experience and medical expertise. Given the available evidence regarding the effectiveness of training in ethical concerns and communication skills near the end of life [5], we suggest that such training should be an obligatory part of medical undergraduate training as well as postgraduate education in oncology to equip oncologists with the relevant professional competences.

\section{References}

${ }_{1}$ Hubert E, Schulte N, Belle S, Gerhardt A, Merx K, Hofmann WK, Stein A, Burkholder I, Hofheinz RD, Kripp M: Cancer patients and advance directives: a survey of patients in hematology and oncology outpatient clinic. Onkologie 2013;36:398-402.

2 In der Schmitten J: Advance care planning: putting an end to the agonizing perpetuation of a pointless debate. Onkologie 2013;36:395-396.

3 Winkler EC, Hiddemann W, Marckmann G: Ethical assessment of life-prolonging treatment. Lancet Oncol 2011;12:720-722.

4 Schildmann J, Ritter P, Salloch S, Uhl W, Vollmann $\mathrm{J}$ : One also needs a bit trust in the doctor...' a qualitative interview study with pancreatic cancer patients about their perceptions and views on - information and treatment decision making. Ann Oncol 2013;24:2444-2449.

5 Kissane DW, Bylund CL, Banerjee SC, Bialer PA, Levin TT, Maloney EK, D'Agostino TA: Communication skills training for oncology professionals. J Clin Oncol 2012;30:1242-1247.

\section{KARGER \\ Fax +497614520714 \\ Information@Karger.com}

www.karger.com (c) 2014 S. Karger GmbH, Freiburg $2296-5270 / 14 / 0372-0060 \$ 39.50 / 0$

Accessible online at: www.karger.com/ort
PD Dr. Jan Schildmann, M.A.

Institute for Medical Ethics and History of Medicine Ruhr-University Bochum

Malakowturm-Markstraße 258a, 44799 Bochum, Germany

jan.schildmann@rub.de 